\title{
TO DETERMINE THE FACTORS PROMOTING FAVOURABLE TREATMENT OUTCOME OF EMPYEMA THORACIS AND COMPLICATED PARAPNEUMONIC EFFUSION
}

\author{
Seema K' Vijay Nair $^{2}$ \\ ${ }^{1}$ Consultant Pulmonologist, Department of Pulmonary Medicine, PVS Memorial Hospital, Kochi. \\ ${ }^{2}$ Assistant Professor, Department of Pulmonary Medicine, Krishna Institute of Medical Sciences.
}

ABSTRACT

\section{BACKGROUND}

The annual incidence of bacterial pneumonia is quite high with $40 \%$ of hospitalised patients have accompanying pleural effusion. The morbidity and mortality rates in patients with pneumonia and pleural effusions are higher than those in patients with pneumonia alone. Early drainage of pus from the pleural cavity along with broad-spectrum antibiotics still remains the cornerstone of treatment. Very few earlier studies have focused on the predicting factors for favourable outcome of parapneumonic effusion and empyema.

\section{MATERIALS AND METHODS}

Study Design- A prospective study. A total of 61 patients with diagnosis of complicated parapneumonic effusion and empyema were enrolled.

Patient's characteristics, comorbidities, duration of symptoms, pleural fluid characteristics and radiological features were noted. All cases were treated with either large bore or small bore chest tubes to drain pleural fluid. Intrapleural Streptokinase was instilled in non-responding patients. Their relation to treatment outcome was evaluated using non-parametric Mann-Whitney U test, Chi-square technique and Fisher's exact test.

\section{RESULTS}

No significant relation exists between presence of comorbidity and outcome; though diabetic patients, smokers and alcoholics had comparatively poorer outcome. All bore pigtail catheters are effective in management of complicated parapneumonic effusion and loculated empyema. Intrapleural streptokinase increases drainage and improves clinical and radiological outcome. Duration of presenting symptom correlates with outcome of tube thoracostomy.

\section{CONCLUSION}

All cases of empyema complicated by bronchopleural fistula are difficult to manage and need surgery.

\section{KEYWORDS}

Parapneumonic Effusion, Empyema, Streptokinase, Tube-Thoracostomy.

HOW TO CITE THIS ARTICLE: Seema K, Nair V. To determine the factors promoting favourable treatment outcome of empyema thoracis and complicated parapneumonic effusion. J. Evolution Med. Dent. Sci. 2018;7(04):429-432, DOI: $10.14260 /$ jemds/2018/95

\section{BACKGROUND}

The annual incidence of bacterial pneumonia is estimated to be about 4 million with approximately $25 \%$ of patients requiring hospitalisation. ${ }^{1}$ As many as $40 \%$ of hospitalised patients with bacterial pneumonia have an accompanying pleural effusion. The possibility of a parapneumonic effusion should be considered each time a patient with acute pneumonia is evaluated. Parapneumonic effusions are often small, but if the depth of the effusion is greater than $10 \mathrm{~mm}$ on the decubitus chest radiograph, a diagnostic thoracentesis should be strongly considered. Before the antibiotic era $60 \%$ - 70\% of cases were caused by Streptococcus pneumoniae, ${ }^{1}$ which now accounts for only about $10 \%$ of culture positive cases. Currently, aerobic organisms are slightly more frequently identified from empyemas. ${ }^{1}$

'Financial or Other Competing Interest': None.

Submission 13-12-2017, Peer Review 06-01-2018,

Acceptance 12-01-2018, Published 22-01-2018.

Corresponding Author:

Dr. Seema K,

14A Shanti Lotus,

BankJunction,

Aluva Ernakulam-683101.

E-mail: seemashyamk@rediffmail.com

DOI: $10.14260 /$ jemds $/ 2018 / 95$
Gram positive organisms most commonly found are those from the streptococcal species including the S. milleri group of organisms and Staphylococcus aureus. ${ }^{2}$ More recently, the reported prevalence of anaerobic infections and Gram negative organisms have increased. Gram negative organisms most commonly implicated in pleural infection include E. coli, Pseudomonas, H. influenza and Klebsiella. These organisms are commonly part of mixed growths with other Gram negative organisms or with anaerobes and rarely occur in isolation. ${ }^{1}$

The morbidity and mortality rates in patients with pneumonia and pleural effusions are higher than those in patients with pneumonia alone. Most pleural effusions associated with pneumonia resolve without any specific therapy directed toward the pleural fluid, but approximately $10 \%$ of patients require operative intervention. Simple chest tube drainage is often inadequate in complicated parapneumonic effusions and empyema. They may require multiple chest tube insertions, radiographically guided catheter placement or uncommonly surgical decortication.

Intrapleural instillation of fibrinolytic agents is undertaken to dissolve fibrinous clots and membranes, to prevent fluid sequestration and hence to improve drainage. Video-assisted techniques offer distinct advantages in the 
accurate staging of the disease process, better management of organising pleural disease and postoperative patient comfort, but are limited by operative risk, cost and local availability.

Despite of all these, there is great variation worldwide in the management of patients with pleural infection and approaches differ between physicians. Aspects such as aetiology, organisms involved, concomitant diseases, prognosis and management differ from series to series.

Several recent trials have addressed some of the key issues in this area, but much is still unclear. Early drainage of pus from the pleural cavity along with broad-spectrum antibiotics still remains the cornerstone of treatment. Very few earlier studies have focused on the predicting factors for favourable outcome of parapneumonic effusion and empyema. In India, the scenario is different compared to West, because of increased prevalence of tuberculosis. No previous study has focused on predicting factors of favourable outcome in complicated parapneumonic effusions and empyema in Indian population and hence the present study was undertaken.

\section{Primary Objective}

To determine the factors promoting favourable treatment outcome of empyema thoracis and complicated parapneumonic effusion.

\section{Secondary Objective}

To identify the common pathogens causing empyema thoracis and complicated parapneumonic effusion.

To study efficacy of intrapleural streptokinase in management of complicated parapneumonic effusion and empyema.

\section{Study Design}

Prospective observational study.

\section{Study Setting}

Pulmonary Medicine Department, Tertiary Care Teaching Hospital, India.

\section{Study Period}

January 2007 - October 2009.

\section{Study Population}

Patient admitted under pulmonary medicine with features suggestive of complicated parapneumonic effusion and empyema requiring intercostal drainage were enrolled in the study.

\section{MATERIALS AND METHODS}

\section{Study Population}

All patients admitted under Department of Pulmonary Medicine with diagnosis of complicated parapneumonic effusion and empyema were enrolled in the study.

\section{Inclusion Criteria}

All patients admitted with complicated parapneumonic effusion and empyema requiring intercostal drainage were taken into study.

\section{Exclusion Criteria}

Empyema due to other causes like secondary to trauma, postsurgery, rupture of amoebic abscess, etc. were excluded from the study.

\section{Study Protocol}

The following data were collected for each patient: Age, gender, clinical symptoms, important underlying diseases, duration of preadmission symptoms, site of effusion, loculations of pleural effusions, leukocyte count and recovery time. The characteristics of pleural effusion including gross appearance, LDH, ADA, Gram's stain, acid-fast stain and culture findings were also recorded. Data related to tube thoracostomy were also recorded including the volume of effusion drained, chest tube size and position and intrapleural streptokinase administration, clearance with streptokinase and any adverse drug effect following streptokinase instillation.

All cases were treated with either large bore or small bore chest tubes to drain pleural fluid tube. In addition to chest radiograph, computerised tomography (CT) or USG of the chest was done for required patients. Intercostal tubes were regularly flushed with normal saline to rule out tube blockage and facilitate maximum drainage.

All patients received a combination of at least two or more antibiotics including penicillin, third generation cephalosporins, metronidazole and aminoglycosides. Fourdrug anti-tuberculosis treatment (ATT) (rifampicin, isoniazid, pyrazinamide and ethambutol) was initiated in cases with tubercular aetiology.

Daily drainage of pleural fluid from the pleural cavity was recorded for each patient. In patients whose drain was less than $50 \mathrm{~mL}$ for 3 consecutive days in spite of adequate positioning and tube patency and repeat CT chest or ultrasound chest was suggestive of residual fluid were treated with intrapleural streptokinase.

Outcome variables taken were clinico-radiological improvement and referral for surgical management.

\section{Statistical Analysis}

Data were collected using a pre-designed data entry sheet. Data was managed on a 'Microsoft Excel' spreadsheet. Analysis was done using statistical software, statistical package for social sciences (SPSS) version.

For continuous variables, normality of distribution was assessed. Normally distributed variables were summarised as median with interquartile range. Continuous variables were compared using non-parametric Mann-Whitney U test. Chisquare technique and Fisher's exact test is used to find the association between categorical variables and the outcome. Statistical significance was considered significant at $P<0.05$ for the present study.

\section{RESULTS \\ Clinical Profile}

In this study, 61 patients (54 males and 7 females) who met the eligibility criteria were enrolled. Males dominated the study group $(n=54,88.5 \%)$. The mean age of the patients was $48.75+/-14.84$ years (range 14 - 82 years) with median 39.5 and IQR 18.5 with majority of the study cohort distributed between 51 - 60 years of age. 
$29(47.5 \%)$ of the patients were smokers. Diabetes mellitus was the commonest co-morbidity and was present in 25 patients (41\%).

Fourteen patients had evidence of previous pulmonary tuberculosis $(22.9 \%)$. Eleven patients had hypertension (18\%). History of neoplasm and renal failure was present in 3 patients each (4.9\%).

Median duration of symptoms was 15 days (range 3 days to 360 days) with IQR 46. Cough was the commonest symptom $(n=50,82 \%)$ followed by fever $(n=44,72 \%)$, chest pain $(n=39,64 \%)$, breathlessness $(n=37,60 \%)$, loss of appetite $(n=23,37.7 \%)$, loss of weight $(n=16,26 \%)$ and haemoptysis $(n=4,0.06 \%)$.

\section{Laboratory Profile}

Biochemical examination of pleural fluid revealed exudative nature of the fluid in all patients with median LDH= 2835 $\mathrm{IU} / \mathrm{L}$ and $\mathrm{ADA}=54.5 \mathrm{IU} / \mathrm{L}$. Based on pleural fluid evaluation patients were diagnosed as: A. Complicated parapneumonic effusion ( $n=14,23 \%)$, B. Simple empyema $(n=21,34.4 \%)$, C. Loculated empyema $(n=26,42.6 \%)$ and D. Pleural fluid pus was present in 47 patients.

\section{Microbiological Characteristics}

Organisms were isolated from 17 cases (27.8\%). Streptococcus pneumoniae was the commonest (12 patients, $19.6 \%$ ). Rest of the patients grew gram-negative organisms, namely Pseudomonas aeruginosa $(n=5)$, Klebsiella pneumoniae $(n=3)$, Staphylococcus $(n=3)$, tuberculosis $(n=2)$ and others $(n=4)$. More than one organism were isolated in three patients. Smear as well as culture for Mycobacterium tuberculosis was positive for 2 patients.

\section{Imaging}

Loculations were seen in 40 patients out of which 14 were complicated parapneumonic effusion and 26 were loculated empyema. Parenchymal lesions suggestive of pulmonary tuberculosis were seen in 13 patients.

\section{Treatment}

ICD was done for all 61 patients. Small bore ICD inserted in 40 patients $(65.5 \%)$, large bore ICD in 21 patients $(34 \%)$ which was based on physician discretion based on pleural fluid characteristic and presence of loculation. Duration of intercostal drain ranged from 4 - 90 days with median of 9 days with IQR 9. Amount of pleural fluid effusion ranged from $100-3100 \mathrm{~mL}$ with median drain of $600 \mathrm{~mL}$ and IQR 1282.5 . Intrapleural streptokinase was instilled in 14 patients with loculated effusion who did not improve with intercostals drain, of whom 11 were cured and 3 referred for surgery. The overall cure rate with streptokinase was $78.5 \%$.

All patients received a combination of antibiotics. Cephalosporin was used in $45(73.7 \%)$ of the patients followed by quinolones in 27 patients (44.2\%), aminoglycoside in 19 (31.1\%) patients and other antibiotics like metronidazole and macrolides.

Twenty eight patients (45.9\%) were given anti-tubercular treatment. All were treated on the basis of clinical history, pulmonary parenchymal lesions strongly suggestive of active tuberculosis and/or mediastinal lymphadenopathy with central necrosis on CT chest with predominantly lymphocytes in differential count and high ADA. Of the 61 patients treated, successful tube thoracostomy drainage was achieved in 50 (82\%) patients. Out of 8 empyema patients who failed, 4 patients had associated Bronchopleural fistula and the rest had organised fluid, which could not be drained with catheter or streptokinase instillation.

\begin{tabular}{|c|c|c|c|c|c|}
\hline \multicolumn{2}{|c|}{} & $\begin{array}{c}\text { Total } \\
(\mathbf{n = 6 1 )}\end{array}$ & $\begin{array}{c}\text { Cured } \\
(\mathbf{n = 5 0 )}\end{array}$ & $\begin{array}{c}\text { Failed } \\
(\mathbf{n = 1 1 )}\end{array}$ & $\begin{array}{c}\text { P } \\
\text { value }\end{array}$ \\
\hline \multirow{3}{*}{$\begin{array}{c}\text { Comor } \\
\text { bidity }\end{array}$} & Smoking & $29(47.5 \%)$ & $23(46 \%)$ & $6(54.5 \%)$ & NS \\
\cline { 2 - 6 } & Alcohol & $25(41 \%)$ & $19(38 \%)$ & $6(54.5 \%)$ & NS \\
\cline { 2 - 6 } & Diabetes & $25(41 \%)$ & $21(42 \%)$ & $4(36.3 \%)$ & NS \\
\cline { 2 - 6 } & Koch & $14(22.9 \%)$ & $11(22 \%)$ & $3(27.2 \%)$ & NS \\
\hline \multicolumn{6}{|c|}{ Table 1. Associated Comorbid Conditions } \\
\hline
\end{tabular}

\begin{tabular}{|c|c|c|c|c|c|}
\hline & $\begin{array}{c}\text { Total } \\
(n=61)\end{array}$ & $\begin{array}{c}\text { Cured } \\
(n=50)\end{array}$ & $\begin{array}{c}\text { Failed } \\
(n=11)\end{array}$ & $P$ value \\
\hline \multirow{4}{*}{ Duration } & Mean & 43.4 & 41 & 54.3 & \multirow{3}{*}{0.016} \\
\hline & Median & 15 & 14 & 39 & \\
\hline & SD & 59.5 & 63.7 & 34.6 & \\
\hline & IQR & 46 & 24.5 & 60 & \\
\hline
\end{tabular}

\begin{tabular}{|l|c|c|c|c|c|}
\hline \multicolumn{2}{|c|}{} & $\begin{array}{c}\text { Total } \\
(\mathbf{n = 6 1 )}\end{array}$ & $\begin{array}{c}\text { Cured } \\
(\mathbf{n = 5 0 )}\end{array}$ & $\begin{array}{c}\text { Failed } \\
(\mathbf{n = 1 1 )}\end{array}$ & \multirow{2}{*}{ P value } \\
\hline \multirow{2}{*}{ Pus } & Positive & $47(77 \%)$ & $37(74 \%)$ & $10(91 \%)$ & \multirow{2}{*}{ NS } \\
\cline { 2 - 4 } & Negative & $14(23 \%)$ & $13(26 \%)$ & $1(9 \%)$ & \\
\hline \multicolumn{3}{|c|}{ Table 3. Appearance of Pleural Fluid of Study Cohort } \\
\hline
\end{tabular}

\begin{tabular}{|c|c|c|c|c|c|}
\hline \multicolumn{2}{|c|}{} & $\begin{array}{c}\text { Total } \\
(\mathbf{n = 6 1 )}\end{array}$ & $\begin{array}{c}\text { Cured } \\
(\mathbf{n = 5 0 )}\end{array}$ & $\begin{array}{c}\text { Failed } \\
(\mathbf{n = 1 1 )}\end{array}$ & $\begin{array}{c}\text { P } \\
\text { value }\end{array}$ \\
\hline \multirow{2}{*}{ Culture } & Positive & $23(37.7 \%)$ & $17(34 \%)$ & $6(54.5 \%)$ & \multirow{2}{*}{ NS } \\
\cline { 2 - 4 } & Negative & $38(62.3 \%)$ & $33(66 \%)$ & $5(45.4 \%)$ & \\
\hline \multicolumn{3}{|c|}{ Table 4. Culture Positivity of Study Cohort } \\
\hline
\end{tabular}

\begin{tabular}{|c|c|c|c|c|c|}
\hline \multicolumn{2}{|c|}{} & $\begin{array}{c}\text { Total } \\
(\mathbf{n = 6 1 )}\end{array}$ & $\begin{array}{c}\text { Cured } \\
(\mathbf{n = 5 0 )}\end{array}$ & $\begin{array}{c}\text { Failed } \\
(\mathbf{n = 1 1 )}\end{array}$ & $\begin{array}{c}\text { P } \\
\text { value }\end{array}$ \\
\hline \multirow{2}{*}{ Loculation } & Present & $40(65.6 \%)$ & $37(74 \%)$ & $3(27.3 \%)$ & \multirow{2}{*}{.005} \\
\cline { 2 - 5 } & Absent & $21(34.4 \%)$ & $13(26 \%)$ & $8(72.7 \%)$ & \\
\hline \multicolumn{2}{|c|}{ Table 5. Imaging Characteristic of Study Cohort } \\
\hline
\end{tabular}

\begin{tabular}{|c|c|c|c|c|c|}
\hline \multicolumn{2}{|c|}{} & $\begin{array}{c}\text { Total } \\
(\mathbf{n = 6 1 )}\end{array}$ & $\begin{array}{c}\text { Cured } \\
(\mathbf{n = 5 0 )}\end{array}$ & $\begin{array}{c}\text { Failed } \\
(\mathbf{n = 1 1 )}\end{array}$ & $\begin{array}{c}\text { P } \\
\text { value }\end{array}$ \\
\hline \multirow{2}{*}{$\begin{array}{c}\text { Type } \\
\text { of ICD }\end{array}$} & Wide bore & $21(34.4 \%)$ & $14(28 \%)$ & $7(63.6 \%)$ & \multirow{2}{*}{0.031} \\
\cline { 2 - 5 } & Small bore & $40(65.5 \%)$ & $36(72 \%)$ & $4(36.3 \%)$ & \\
\hline \multicolumn{5}{|c|}{ Table 6. ICD Modalities of Study Cohort } \\
\hline
\end{tabular}

\begin{tabular}{|c|c|c|c|c|}
\hline \multicolumn{2}{|l|}{} & $\begin{array}{c}\text { Total } \\
(\mathbf{n = 6 1 )}\end{array}$ & $\begin{array}{c}\text { Cured } \\
(\mathbf{n = 5 0 )}\end{array}$ & $\begin{array}{c}\text { Failed } \\
(\mathbf{n = 1 1})\end{array}$ \\
\hline $\begin{array}{c}\text { Streptokinase } \\
\text { Instillation }\end{array}$ & Yes & $14(23 \%)$ & $11(22 \%)$ & $3(27.3 \%)$ \\
\cline { 2 - 5 } Table 7. Intrapleural Streptokinase Instillation \\
of Study Cohort
\end{tabular}

\begin{tabular}{|c|c|c|c|c|c|}
\hline \multicolumn{2}{|c|}{} & $\begin{array}{c}\text { Total } \\
(n=61)\end{array}$ & $\begin{array}{c}\text { Duration } \\
<13 \text { days }\end{array}$ & $\begin{array}{c}\text { Duration } \\
\text { > 13 days }\end{array}$ & $\begin{array}{c}\text { P } \\
\text { value }\end{array}$ \\
\hline \multirow{2}{*}{$\begin{array}{c}\text { Type of } \\
\text { ICD }\end{array}$} & $\begin{array}{c}\text { Wide } \\
\text { bore }\end{array}$ & $21(34.4 \%)$ & $9(20.5 \%)$ & $12(70.6 \%)$ & \multirow{2}{*}{0.00} \\
\cline { 2 - 6 } & $\begin{array}{c}\text { Small } \\
\text { bore }\end{array}$ & $40(65.6 \%)$ & $35(79.5 \%)$ & $5(29.4 \%)$ & \\
\hline $\begin{array}{c}\text { Strepto- } \\
\text { kinase } \\
\text { Instillation }\end{array}$ & Yes & $14(23 \%)$ & $13(29.5 \%)$ & $1(5.9 \%)$ & \multirow{2}{*}{0.04} \\
\cline { 2 - 5 } & No & $31(77 \%)$ & $31(70.5 \%)$ & $16(94.1 \%)$ & \\
\hline \multicolumn{7}{|c|}{ Table 8. Effect of Procedures done on Duration of } \\
Intercostal Drain
\end{tabular}




\begin{tabular}{|c|c|c|c|}
\hline & $\begin{array}{c}\text { Total } \\
(\mathbf{n = 6 1 )}\end{array}$ & $\begin{array}{c}\text { Cured } \\
(\mathbf{n = 5 0 )}\end{array}$ & $\begin{array}{c}\text { Failed } \\
(\mathbf{n = 1 1})\end{array}$ \\
\hline $\begin{array}{c}\text { Diagnosis } \\
\text { Complicated } \\
\text { Parapneumonic Effusion }\end{array}$ & $14(23 \%)$ & $13(26 \%)$ & $1(1 \%)$ \\
\hline Empyema & $21(34.4 \%)$ & $13(26 \%)$ & $8(72.7 \%)$ \\
\hline Loculated Empyema & $26(42.6 \%)$ & $24(48 \%)$ & $2(18.2 \%)$ \\
\hline \multicolumn{2}{|c|}{ Table 9. Outcome of Tube Thoracostomy } \\
\hline
\end{tabular}

\section{DISCUSSION}

In the present study males outnumbered female patients, especially in the 50 - 60 years' age group, even though we did not find any statistically significant correlation with outcome. This finding is consistent with the experience with Geha et al, whose study also showed incidence of empyema to be higher after the age of 40 .

In our study, most common symptom was cough ( $(50 / 61$, $82 \%$ ) followed by fever (44/61, 72\%), which was similar to study by $\mathrm{T}$ Preetam et $\mathrm{al}^{3}$ and Kamat et al where cough was most common (92.5\% and $94 \%$ respectively) followed by fever.

The mean duration of presenting symptom was 41 days and was found to be statistically significant when related to outcome: Longer duration of symptoms having poor outcome with tube thoracostomy, which was earlier proposed by Moran. 4 This is attributed to progression of effusion to fibrotic stage, where tube thoracostomy and intrapleural streptokinase are less likely to be effective.

We found no significant relation between presence of comorbidity and outcome. Though diabetic patients, smokers and alcoholics had comparatively poorer outcome, but it was not statistically significant.

In our study, pleural fluid culture was positive in only $17 / 61(27.8 \%)$ patients with Streptococcus pneumoniae being the most common organism (18\%) cases. Our poor culture yield was attributed to antibiotic exposure prior to hospitalisation as our hospital being a referral centre and increased incidence of tuberculosis empyema in Indian setting.

In our study, twenty eight cases (45.9\%) were suspected as tubercular empyema and started on ATT. A small proportion of cases of tubercular empyema could be diagnosed by isolation of AFB in sputum and/ or pleural pus. In addition, a large number were diagnosed on the basis of past history, symptomatology, radiological lesions and therapeutic response to anti-tuberculous treatment which was similar to previous studies. In a study by Amit Banga et $\mathrm{al}, 5$ tubercular aetiology was found in 13 patients (42\%).

In our study, no difference in procedure success rates was observed between culture proven empyema or parapneumonic effusion which was similar to study of LeMense et al,6 which also observed no difference in procedure success rates or hospital stay between multiloculated and uniloculated empyemas, parapneumonic and non-parapneumonic empyemas. Our success rate with pigtail catheter was $90 \%(36 / 40)$. We had better outcome with small bore pigtail, which could be attributed to use of streptokinase instillation in patients with loculated effusion having small bore catheter and also most of small bore catheters were placed under CT/ USG guidance, which had an added advantage.
Out of 14 patients treated with intrapleural streptokinase, we had good outcome in 11 patients (78.5\%). Our study showed that streptokinase group had an increasing volume of chest tube drainage, a decreasing time of defervescence and a shorter hospital stay.

All successful procedures (pigtail and streptokinase instillation) in our study resulted in shorter ICD duration and hospitalisations, which was statistically significant except for patients with empyema with BPF requiring decortication.

The success rate for conventional tube thoracostomy drainage is $32 \%$ to $71 \%$. In our study, the success rate of tube thoracostomy was $82 \%$ (50/61). Our better outcome was attributed to prompt drainage along with streptokinase instillation. Our study had more failure cases in empyema group which was contradicting previous studies that empyema had better outcome compared to loculated empyema. This difference in outcome was attributed to associated Bronchopleural fistula present in $50 \%$ of our empyema patients.

We did not encounter any mortality in our study.

\section{CONCLUSION}

- No significant relation between presence of comorbidity and outcome, though diabetic patients, smokers and alcoholics had comparatively poorer outcome.

- All bore pigtail catheters are effective in management of complicated parapneumonic effusion and loculated empyema.

- Even in patients with late stage of empyema thoracis, intrapleural streptokinase appears to be a useful strategy to preserve lung function and reduces need for surgery.

- Intrapleural streptokinase is safe, increases drainage and improves clinical and radiological outcome.

- Interventions like pigtail catheters and intrapleural streptokinase significantly reduces the duration of treatment of complicated parapneumonic effusion and loculated empyema.

- Duration of presenting symptom correlates with outcome of tube thoracostomy.

- All cases of empyema complicated by bronchopleural fistula are difficult to manage and needed major surgery.

\section{REFERENCES}

[1] Light RW. Parapneumonic effusions and Empyema. In: Pleural diseases. 5th edn. New Delhi, Lippincott Williams and Wilkins, 2007:179-84.

[2] Ashbaugh DG. Empyema thoracis. Factors influencing morbidity and mortality. Chest 1991;99(5):1162-5.

[3] Acharya PR, Shah KV. Empyema thoracis: a clinical study. Ann Thorac Med 2007;2(1):14-7.

[4] Moran JF. Surgical management of pleural space infections. Semin Respir Infect 1988;3(4):383-94.

[5] Banga A, Khilnani GC, Sharma SK, et al. A study of empyema thoracis and role of intrapleural streptokinase in its management. BMC Infect Dis 2004;4:19.

[6] LeMense GP, Strange C, Sahn SA. Empyema thoracic. Therapeutic management and outcome. Chest 1995;107(6):1532-7. 